\title{
Spontaneous twin pregnancy with live births after cryopreservation and re-implantation of ovarian tissue
}

\author{
Milan Milenkovic ${ }^{1,5^{*}}$, Mats Brännström', Cesar Diaz-Garcia ${ }^{2,3}$, Kersti Lundin', Ulrika Selleskog ${ }^{1}$, Brita Söderlund ${ }^{1}$,

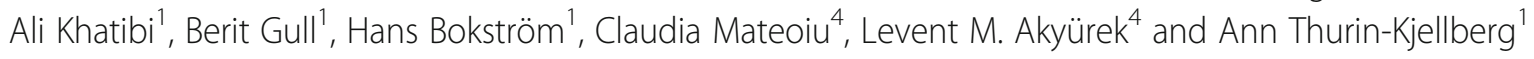

Keywords: Fertility preservation, Ovarian transplantation, Pregnancy, Twin, Livebirth

\section{Background}

Ovarian tissue cryopreservation (OTC) before gonadotoxic treatment and subsequent avascular auto-transplantation is a method of fertility preservation in cancer patients, with first birth reported in 2004 [1]. This method has resulted in more than 85 livebirths worldwide [2-4], with delivery rate of $25-32 \%$ per transplanted woman [2, 3].

\section{Methods}

A 27-year-old, 1-parous patient suffered from Hodgkin's lymphoma in 2011. Pre-operative transvaginal sonography (TVS) revealed a normal uterus, the left side ovary with a unilocular cyst of $50 \times 70 \mathrm{~mm}$ and the right ovary with 8 antral follicles. Laparoscopic stripping of left ovarian cyst and right-sided oophorectomy was performed with subsequent standard OTC of 15 cortical strips [5] before six chemotherapy treatments with BEACOPP (bleomicin, etoposide, adryamicin, cyclophosphamide, oncovin, procarbazine, prednisolone). Histology showed benign mucinous cystadenoma. After chemotherapy, patient experienced amenorrhea and climacteric symptoms that were treated by hormonal replacement therapy (HRT). HRT was ceased in October 2013 due to benign cysts in the breast, and the patient developed oligomenorrhea. Hormonal status after chemotherapy is presented in Fig. 1a. Patient was considered free of disease and tried to conceive for 1 year. In March 2015, TVS showed cyst on the left ovary and laparoscopic

\footnotetext{
* Correspondence: milan.d.milenkovic@gmail.com

${ }^{1}$ Department of Obstetrics and Gynecology, Sahlgrenska Academy Hospital, University of Gothenburg, Gothenburg, Sweden

${ }^{5}$ Department of Obstetrics and Gynecology, Karolinska University Hospital, Stockholm, Sweden

Full list of author information is available at the end of the article
}

excision of the cyst and cortex biopsy was performed. Histology of the cortex showed 0.2 primordial follicles $(\mathrm{PF}) / \mathrm{mm}^{2}$ and cyst without atypia. Patient consented to re-implant cryopreserved ovarian tissue. Tissue was thawed, and histology demonstrated $8-10 \mathrm{PF} / \mathrm{mm}^{2}$ and no atypical cells. A mini-laparotomy through Pfannenstiehl incision and re-implantation of thawed ovarian tissue was performed in May 2015. Four pieces were reimplanted in subcortical pockets of the left ovary (Fig. 1b) [2], and due to the small remaining ovary, three pieces were placed under the peritoneum of the right mesosalpinx [1]. On the day of cortex re-implantation, hormonal status confirmed ovarian failure (Fig. 1a). TVS showed no antral follicles.

\section{Findings}

Menstrual bleedings occurred 21, 40, and 51 days after re-implantation. Thirty days after the surgery, TVS demonstrated corpus luteum on the left ovary, and the transplant measured $15 \times 8 \times 11 \mathrm{~mm}$ on the right side. Progesterone level was $28 \mathrm{nmol} / \mathrm{l}$. TVS on day 112 after re-implantation demonstrated triple endometrium on $7 \mathrm{~mm}$, two antral follicles on the left ovary, and one follicle on the right side. One hundred thirty-four days after re-implantation, TVS confirmed spontaneous viable dichoriotic diamniotic twin intrauterine pregnancy corresponding to pregnancy week $5+4$. Spontaneous vaginal delivery occurred at gestational week $37+2$ of a healthy girl and boy weighing 2085 and 2480 g, respectively. Nineteen months after transplantation, the patient has regular menstrual bleeding. 


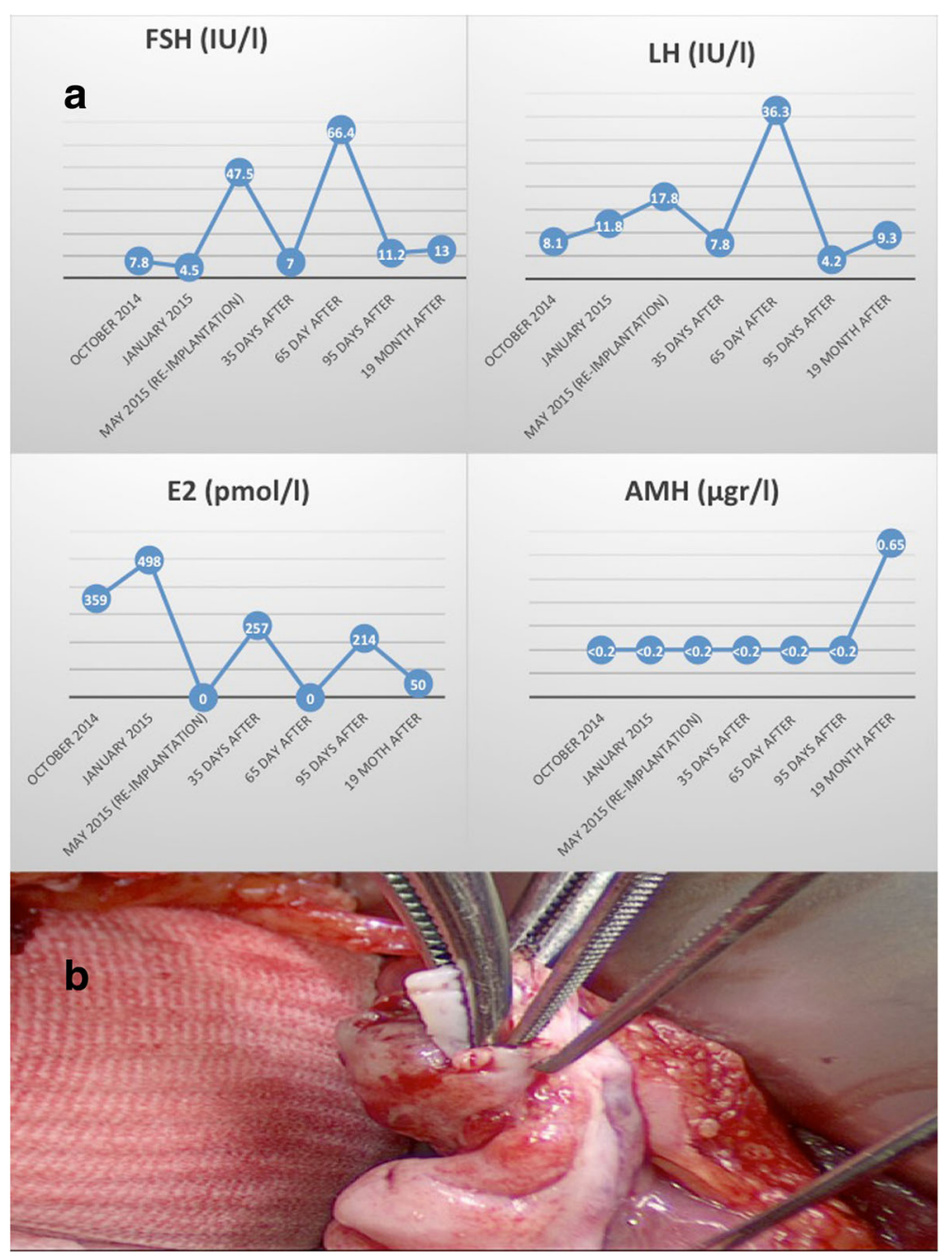

Fig. 1 a Hormonal status after chemotherapy (follicle stimulating hormone (FSH); luteinising hormone (LH); estradiol (E2); anti-Müllerian hormone $(\mathrm{AMH}))$. $\mathbf{b}$ Re-implantation of thawed ovarian tissue in subcortical pocket of the left ovary

\section{Discussion}

To our best knowledge, we report a first spontaneous twin pregnancy after OTC and auto-transplantation. Twin pregnancies and livebirths following OTC and IVF were published before [4]. Estradiol production by ovarian cyst can explain normal gonadotropin level 4 months before re-implantation. Gonadotropins increased to castrated level after cyst excision (Fig. 1a). We cannot completely rule out the possibility that early bleeding pattern reflected hormonal activity of the native ovary. However, pregnancy was already reported 2 months after ovarian tissue transplantation [3]. Regular menstrual pattern after delivery confirms graft hormonal function. Reimplantation may be performed by laparoscopy or by laparotomy [1-4]. We choose surgery by 6 -cm laparotomy using surgical loops and respecting microsurgical rules, after our experience on uterus transplantation and animal experiments [6,7]. Otherwise, this is the first auto-transplantation performed at Sahlgrenska Academy Hospital since the OTC program was introduced in 1995.

\section{Acknowledgements}

Nil.

\section{Funding}

No funding was required.

\section{Authors' contributions}

MM performed the project development, surgery, and manuscript writing. MB performed the project development and surgery. CDG performed the surgery. KL performed the project development and manuscript writing. US and BS performed the laboratory work. AK performed the data collection and manuscript writing. $B G, H B$, and $C M$ performed the data collection. LMA performed the data collection and manuscript writing. AT-K performed the project development and manuscript writing. All authors read and approved the final manuscript.

\section{Competing interests}

The authors declare that they have no conflict of interests. 


\section{Consent for publication}

This is a case report with no identifiable data. Informed consent was not obtained.

\section{Ethics approval and consent to participate}

This is not applicable for this study.

\section{Author details}

'Department of Obstetrics and Gynecology, Sahlgrenska Academy Hospital, University of Gothenburg, Gothenburg, Sweden. ${ }^{2}$ Department of Obstetrics and Gynecology, La Fe University Hospital, University of Valencia, Valencia, Spain. ${ }^{3}$ Human Reproduction Research Group, IIS La Fe, Valencia, Spain. ${ }^{4}$ Department of Clinical Pathology and Genetics, Sahlgrenska Academy Hospital, University of Gothenburg, Gothenburg, Sweden. ${ }^{5}$ Department of Obstetrics and Gynecology, Karolinska University Hospital, Stockholm, Sweden.

Received: 22 February 2017 Accepted: 2 June 2017

Published online: 14 June 2017

\section{References}

1. Donnez J, Dolmans MM, Demylle D, Jadoul P, Pirard C, Squifflet J et al (2004) Livebirth after orthotopic transplantation of cryopreserved ovarian tissue. Lancet 364:1405-1410

2. Meirow D, Ra'anani H, Shapira M, Brenghausen M, Derech Chaim S, Aviel-Ronen S et al (2016) Transplantations of frozen-thawed ovarian tissue demonstrate high reproductive performance and the need to revise restrictive criteria. Fertil Steril 106:467-474

3. Van der Ven H, Liebenthron J, Beckmann M, Toth B, Korell M, Krussel J et al (2016) Ninety-five orthotopic transplantations in 74 women of ovarian tissue after cytotoxic treatment in a fertility preservation network: tissue activity, pregnancy and delivery rates. Hum Reprod 31:2031-2041

4. Jensen AK, Macklon KT, Fedder J, Ernst E, Humaidan P, Andersen KY (2017) 86 successful births and 9 ongoing pregnancies worldwide in women transplanted with frozen-thawed ovarian tissue: focus on birth and perinatal outcome in 40 of these children. J Assist Reprod and Genet 34:325-336

5. Gosden RG, Baird DT, Wade JC, Webb R (1994) Restoration of fertility to oophorectomized sheep by ovarian autografts stored at -196 degrees C. Hum Reprod 9:597-603

6. Brannström M, Johannesson L, Bokström H, Kvarnström N, Mölne J, Dahm-Kahler P et al (2014) Livebirth after uterus transplantation. Lancet 385(9968):607-616

7. Diaz-Garcia C, Milenkovic M, Groth K, Dahm-Kahler P, Olausson M, Brannstrom M (2011) Ovarian cortex transplantation in the baboon: comparison of four different intra-abdominal transplantation sites. Hum Reprod 26:3303-3311

\section{Submit your manuscript to a SpringerOpen ${ }^{\circ}$ journal and benefit from:}

- Convenient online submission

- Rigorous peer review

- Open access: articles freely available online

- High visibility within the field

- Retaining the copyright to your article 